\title{
METABOLIC EFFECTS OF MARKED SODIUM RESTRICTION IN HYPERTENSIVE PATIENTS. SKIN ELECTROLYTE LOSSES ${ }^{1}$
}

\author{
By LEWIS K. DAHL, BERNARD G. STALL, III, AND GEORGE C. COTZIAS \\ (From the Medical Department, Brookhaven National Laboratory, Upton, L. I., N. Y.)
}

(Submitted for publication August 15, 1954; accepted November 24, 1954)

The increasing use of prolonged $\mathrm{Na}$ restriction in the treatment of cardiovascular diseases in particular, makes study of long-term $\mathrm{Na}$ balance pertinent. With diets which contain 2 to $7 \mathrm{mEq}$. $\mathrm{Na}$ per day, combined urine and stool losses average 1 to $5 \mathrm{mEq}$. $\mathrm{Na}$ per day $(1,2)$. Therefore, over an extended period the loss of electrolyte through the skin might assume importance. Only two earlier studies were found relative to electrolyte losses of the entire skin, both after shortterm $\mathrm{Na}$ restriction, namely 3 (3) and 14 (4) days.

The data from Benedict's classical study (5) of an individual who fasted for one month have relevance to any work on the physiological response to dietary restriction, but the metabolic effects of starvation are not directly applicable to those effected by limitation of only two dietary components-namely sodium and chloride.

For almost seven years the authors of the present paper have been using a diet which contains about $6 \mathrm{mEq}$. $\mathrm{Na}$ per day in the study and treatment of patients with essential hypertension. On such a regimen combined urine and stool losses average 2 to $5 \mathrm{mEq}$. $\mathrm{Na}$ per day, and since no evidence of hyponatremia had been found in the absence of serious renal disease, it was reasonable to suppose that the patients were in $\mathrm{Na}$ balance. The current study was undertaken to quantitate the actual skin losses of several electrolytes on seven subjects who had been on the low $\mathrm{Na}$ regimen for one to five months, during two collection periods of 7 and 3 days. Although interest was centered primarily on $\mathrm{Na}, \mathrm{Cl}$ and $\mathrm{K}$ were measured as well.

\section{MATERIAL}

The seven white adult subjects had been admitted to the metabolic wards of the Brookhaven National Laboratory Hospital for studies relative to the hypertension

\footnotetext{
1 This research was sponsored by the Atomic Energy Commission.
}

research program. The pertinent clinical and laboratory data on these patients are summarized in Table $I$. It will be seen that five of the patients, all females, had classical uncomplicated benign hypertension. In two (Di, Jo), the blood pressure had attained near-normal levels by the end of the six-week control period and before $\mathrm{Na}$ restriction had begun. The male with malignant hypertension had had a bilateral lumbar sympathectomy in 1952 without significant effect on the course of his disease. This patient on admission had severe headaches, intermittent gallop rhythm, and impairment of renal function. The seventh subject, a female of fortyfive, was a normal volunteer who underwent precisely the regimen of these hypertensive patients for a fifteenweek period. At the beginning of the first experiment, patient $\mathrm{Bl}$ had been on the low $\mathrm{Na}$ regimen for 150 days, patient Os for 40 , and the remaining five for 26 days.

\section{PROCEDURE}

\section{Diet; Urines}

All patients were on a diet accurately calculated and weighed daily with an intake of approximately $6 \mathrm{mEq}$. $\mathrm{Na}$ per day ${ }^{2}(5.7 \pm 1.4 \mathrm{mEq}$.) by analysis of 18 daily diets. ${ }^{3}$ Restriction of $\mathrm{Na}$ to this amount allowed 45 to 55 grams of protein per day in the food; the intake was therefore supplemented with the low $\mathrm{Na}$ protein foods Lesofac 4 or Lonalac(8) in amounts sufficient to give a total of 1.5 grams protein per $\mathrm{Kg}$. body weight per day. $\mathrm{K}$ and $\mathrm{Cl}$ were not included in the daily calculations and therefore their amounts were primarily dependent upon the limitations imposed by the low Na. Analysis of the

2 During the period of control, $10 \mathrm{gm}$. of enteric coated $\mathrm{NaCl}$ had been taken by each patient daily in addition to this basic diet.

${ }^{3}$ These analyses were carried out at various times during the year preceding this experiment. Recently, after the completion of this study, analyses were done on six seven-day collections which were made during the period of June 6 to 28 . The average value was $4.6 \mathrm{mEq}$. $\mathrm{Na}$ per day (range $4.3-4.7$ ). The electrolyte content of vegetables will vary with the content in the soil in which grown (6) and the source of supply will of course vary with the season. Because the previous analyses were done over a longer period, it is believed that they are more representative of the average intake, and in this study the value of $6 \mathrm{mEq}$. per day has been assumed.

4 Obtained through the courtesy of Wyeth \& Co., Philadelphia. 


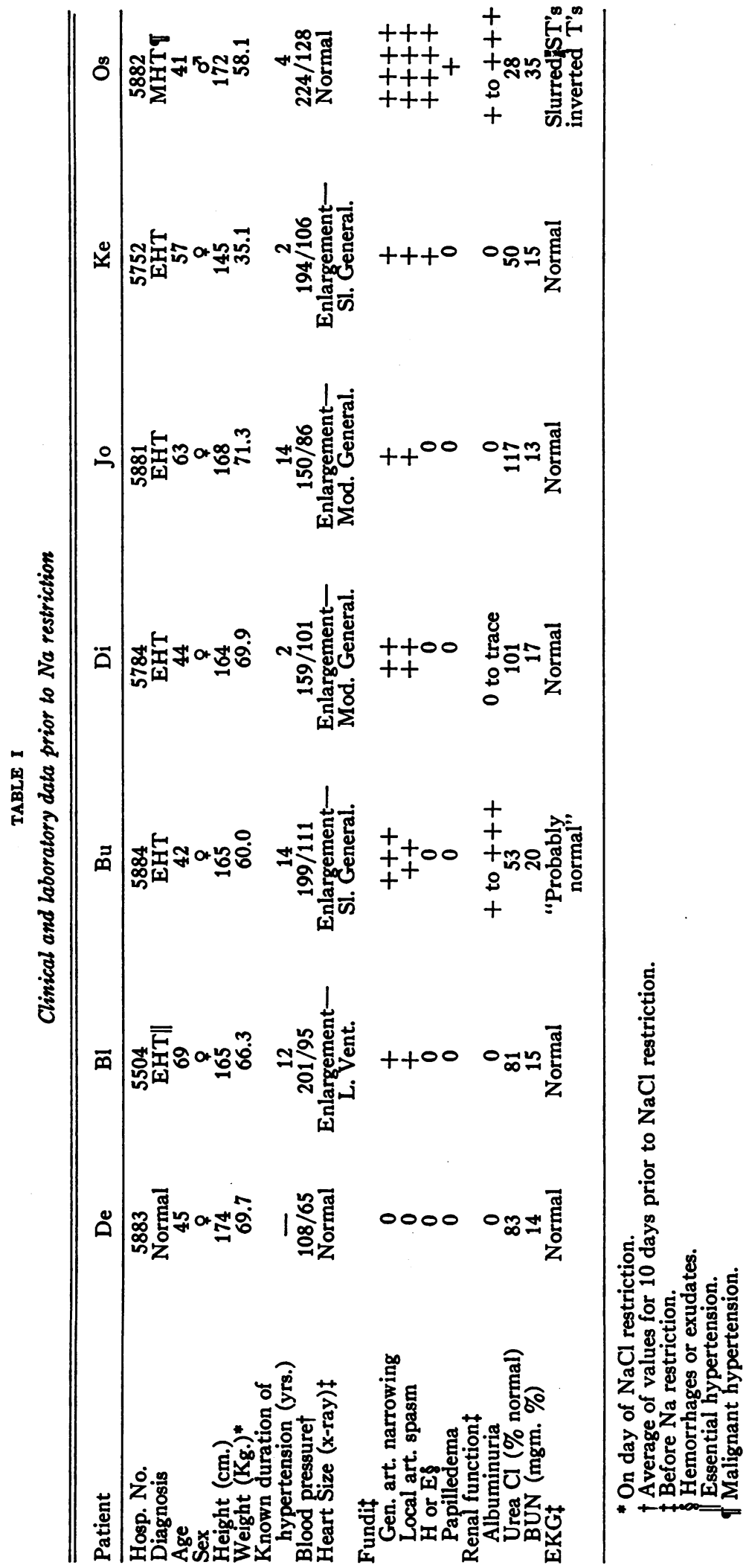


diets yielded an average of $70 \mathrm{mEq} . \mathrm{K}$ (range 30 to 100 ) and $12 \mathrm{mEq}$. $\mathrm{Cl}$ (range 9 to 15 ) per day. Thus the diet in effect provided a low $\mathrm{Na}$, low $\mathrm{Cl}$, normal $\mathrm{K}$ intake. All urines were saved, pooled for measurement of 24hour volume, $200 \mathrm{ml}$. aliquots removed, and then preserved with $1 \mathrm{ml}$. of concentrated $\mathrm{H}_{2} \mathrm{SO}_{4}$.

\section{Experimental procedure}

Preparation of patients and clothing. On the first day of both experiments each patient had a shower using an ion-free detergent, Brij $35,{ }^{5}$ and wash rag to scrub the entire skin and hair. This was followed by repeated rinses with distilled water after which the patient was dried with a towel previously washed in the above detergent and tap water. Closely fitting one-piece cotton underwear was then put on which extended to the wrists and ankles. Both underwear and wash rags had been extracted as follows: an initial wash in an automatic washer with tap water and Brij 35, rinsed thoroughly in $0.1 \mathrm{NH}_{2} \mathrm{SO}_{4}$, three rinsings of tap water, left overnight in acidified (with $\mathrm{H}_{2} \mathrm{SO}_{4}$ ) distilled water, then rinsed at least three times in distilled water and until the wash fluid had less than $0.04 \mathrm{mEq}$. Na per liter as tested by the direct technique on a Baird Model DB2 flame photometer. No $\mathrm{K}$ was found by the same method of testing. Over the underwear, loosely fitting cotton surgical pants and shirts tied at the wrists, ankles and neck were worn. Short white cotton sox and surgical turbans completed the outfit except for their individual foot gear. The pants, gown, sox and head coverings had been washed with Brij 35 in tap water but had not been chemically extracted. The shoes and slippers had not been treated in any fashion.

\section{Experimental periods}

Collections were made during two periods of seven and three days, the end of the first and start of the second being separated by eleven days. Until completion of each of the experimental periods, none of the garments were removed except the shoes at night. The patients were instructed as follows: 1 . The hands and face could be washed as necessary with tap water and a 1:500 solution of Brij $35 ; 2$. After each bowel movement, and urination in the females, the perineal urea was to be washed with Brij 35 and rinsed with distilled water; 3. No beauty aids, deodorants, or other toilet preparations could be applied; 4. Normal activities could be maintained including outdoor strolls and occupational therapy projects providing no frank sodium contamination was involved (e.g., clay modeling or washing clothes with soap or high-sodium detergents was not allowed); 5. Vigorous exercise was to be avoided. The patients were highly cooperative and individually interested in these studies and it is believed maximal attempts were made to live up to these stipulations.

Ward temperatures were maintained at 72 to $74^{\circ} \mathrm{F}$. during the day and from 65 to $68^{\circ}$ at night. After the

5 Donated by the Atlas Powder Co., kindness of S. J. Dumovich. studies were completed, it was found that the average maximal daily temperatures outside averaged $50.7^{\circ} \mathrm{F}$. and $62.6^{\circ} \mathrm{F}$. during the seven and three-day studies, respectively.

\section{Collection of samples}

(a) Bath water. At the end of each experimental period, the perineal area was washed as described previously and washings discarded. Thereafter the washing procedure was carried out under direct supervision by one of the authors or a thoroughly trained nurse. The outer garments including foot gear, sox, turbans, shirts and pants were removed and not used in the subsequent analyses. Before removing the underwear, the face, neck, hands and feet were washed with Brij solution, rinsed with distilled water, and the washings discarded; it had been decided previously that contamination of these areas during the studies could not be prevented and therefore they were eliminated from the calculations. The underwear was then removed and placed in a clean wax bag. For collection of bath washings, a chemically clean stainless steel tub slightly over two feet in all diameters was provided, with a special drain from which all wash fluid went directly into collecting bottles. Using sponge bath technique, each patient washed the entire body including scalp with the Brij solution and a wash rag previously extracted in the manner used for underwear. Three complete rinses with distilled water followed after which the patient methodically wiped the inside of the tub with the wash rag which was then placed in the bag with the underwear. The empty tub was thoroughly rinsed with $0.1 \mathrm{~N} \mathrm{H}_{2} \mathrm{SO}_{4}$, followed by distilled water, and these rinses added to the bath water. After mixing, the total volume was measured and for the group averaged 4.7 liters. Two hundred $\mathrm{ml}$. aliquots were preserved with $1 \mathrm{ml}$. of concentrated $\mathrm{H}_{2} \mathrm{SO}_{4}$.

(b) Extraction of underwear and wash rags. These items were treated individually by an initial extraction with Brij solution, then three extractions with $0.1 \mathrm{~N}$ $\mathrm{H}_{2} \mathrm{SO}_{4}$ at which time the washings uniformly had not more than $0.04 \mathrm{mEq}$. $\mathrm{Na}$ per liter and no $\mathrm{K}$, tested in the same fashion as before. All of these extracting solutions for each patient were pooled, the volume measured, and analyzed separately from the bath water so that if widely disparate results in the analysis of bath and extracting solutions had occurred, evidence of contamination would have been suggested. The volumes of the extraction fluids averaged 5.6 liters for the group. Aliquots were removed and preserved in the usual fashion.

\section{Methods}

Sodium and potassium. $\mathrm{Na}$ and $\mathrm{K}$ analyses were made with a Baird Model DB2 flame photometer using an internal lithium standard. Recovery experiments repeatedly gave maximal errors of 1 per cent. Depending upon the concentration of $\mathrm{Na}$ or $\mathrm{K}$ in the samples, 1 to $40 \mathrm{ml}$. of solution diluted to $100 \mathrm{ml}$. were analyzed in duplicate, with recalibration of the instrument against standard solutions at least every second sample. 


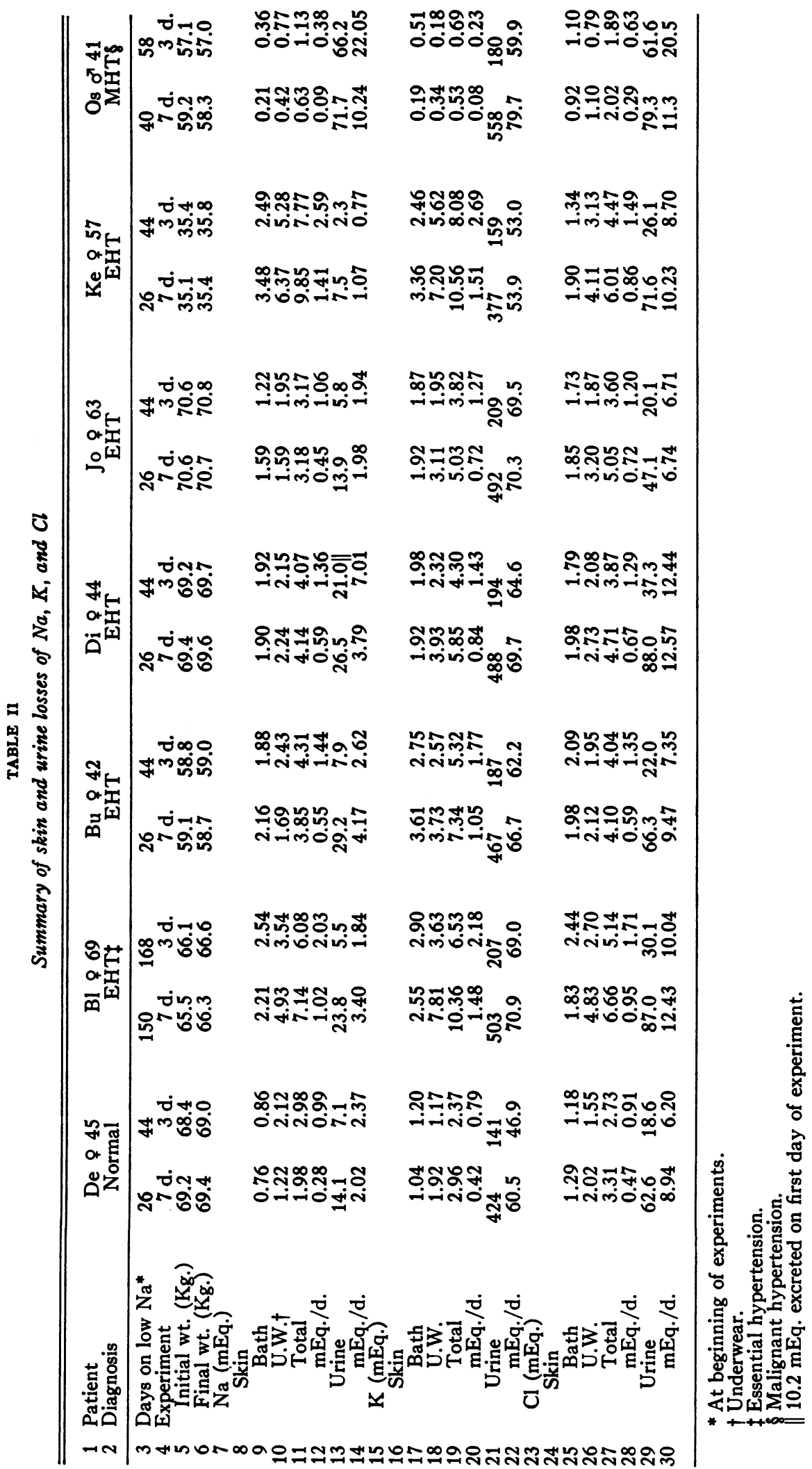


Chloride. The Van Slyke and Hiller modification (7) of Sendroy's method (8) with the nomogram of Van Slyke (9) for solubility corrections of $\mathrm{Ag} \mathrm{IO}$, was used; because of the low $\mathrm{pH}$ of the solutions (1.5 to 2.0) from the $\mathrm{H}_{2} \mathrm{SO}_{4}$ preservative, upon the advice of Dr. D. D. Van Slyke, no $\mathrm{H}_{8} \mathrm{PO}_{4}$ was added. Furthermore, because of the low chloride in most solutions, $25 \mathrm{ml}$. aliquots were precipitated. All analyses were done in a constant temperature room maintained at $20^{\circ} \mathrm{C}$. Experiments with standard added to these solutions gave 98.3 to 100.5 per cent recovery ( 99.4 per cent average) but as a further check on reagents and method, standard solutions were analyzed at the beginning and end of each day's titrations.

\section{OBSERVATIONS}

The primary data on skin and urine losses of $\mathrm{Na}, \mathrm{K}$, and $\mathrm{Cl}$ are shown in Table II.

\section{Sodium-Skin}

It may be seen that despite variation within the group, daily loss of $\mathrm{Na}$ from the skin in all individuals was low, ranging from 0.09 to $2.59 \mathrm{mEq}$. (line 12 ) but with the majority about 0.5 to 1.5 $\mathrm{mEq}$. per day. The highest daily losses in both seven and three-day experiments (1.41 and 2.59 $\mathrm{mEq}$., respectively) were in the smallest individual $(\mathrm{Ke})$ and the lowest values $(0.09$ and $0.38 \mathrm{mEq}$, respectively) in the one patient (Os) with malignant hypertension. Skin losses in the normal control patient (De) were roughly half way $(0.28$ and $0.99 \mathrm{mEq}$. per day) between the lowest values and the mean ( 0.80 and $1.70 \mathrm{mEq}$. per day) of the five patients with essential hypertension, as well as being less than losses of any individual among those five. That significant contamination did not occur in these experiments is suggested by the generally low total values for $\mathrm{Na}$ as well as by the lack of striking disparity between $\mathrm{Na}$ values for bath and underwear (lines 9 and 10).

\section{Sodium-Urine}

Urinary excretion of $\mathrm{Na}$ is summarized in lines 13 and 14. With the exception of patient Os with malignant hypertension, the values found were within the range observed in hypertensive patients during the past six years on this same regimen, namely about 1 to $4 \mathrm{mEq}$. per day. The value of $7 \mathrm{mEq}$. per day shown by patient Di during the three-day experiment lies within the range of dayto-day fluctuation in the urinary excretion of $\mathrm{Na}$ in patients maintained on a constant low $\mathrm{Na}$ in- take. The normal control did not differ from the five patients with essential hypertension in her ability to conserve $\mathrm{Na}$ on a restricted intake. $\mathrm{Pa}$ tient Os, with serious renal disease, excreted an average of 10 and $22 \mathrm{mEq}$. per day in these two experiments. It may be recalled that this patient was shown to lose phenomenally small amounts of $\mathrm{Na}$ from the skin-considerably less than the six subjects with good renal function. By contrast, patient $\mathrm{Ke}$, who had the largest skin loss of $\mathrm{Na}$, had the smallest urinary loss (1.07 and $0.77 \mathrm{mEq}$. per day).

\section{Potassium-Skin}

In general, the findings paralleled closely those described above for $\mathrm{Na}$. Potassium loss was only slightly greater than that of $\mathrm{Na}$ with a range of 0.08 to $2.69 \mathrm{mEq}$. per day (line 20 ) in the group. The five patients with essential hypertension averaged 1.1 and $1.9 \mathrm{mEq}$. per day, the normal control 0.42 and $0.79 \mathrm{mEq}$. per day, and patient Os 0.08 and $0.23 \mathrm{mEq}$. per day with the seven and three-day experiments, respectively. Thus, ranked by absolute daily losses, the seven members were distributed in the same order found for $\mathrm{Na}$ loss in skin. And again, patient $\mathrm{Ke}$ had the greatest loss in both experiments, as patient Os had the least.

\section{Potassium-Urine}

The $\mathrm{K}$ intake of 30 to $100 \mathrm{mEq}$. per day is reflected in the large urinary excretions shown in lines 21-22 and did not appear to be correlated with the condition of individual patients.

\section{Chloride-Skin}

The previously described low values for $\mathrm{Na}$ and $\mathrm{K}$ skin loss were imitated by those for $\mathrm{Cl}$ in that only 0.29 to $1.71 \mathrm{mEq}$. per day were measured (line 28). The five patients with essential hypertension were grouped closely about an average of 0.8 and $1.4 \mathrm{mEq}$. per day with the control slightly lower ( 0.47 and $0.91 \mathrm{mEq}$.) and patient Os, lowest, with 0.29 and $0.63 \mathrm{mEq}$. per day.

\section{Chloride-Urine}

Except for the three-day period with patient Os, excretion was from 6.20 to $12.57 \mathrm{mEq}$. per day. No definite correlations with clinical status were evident. 


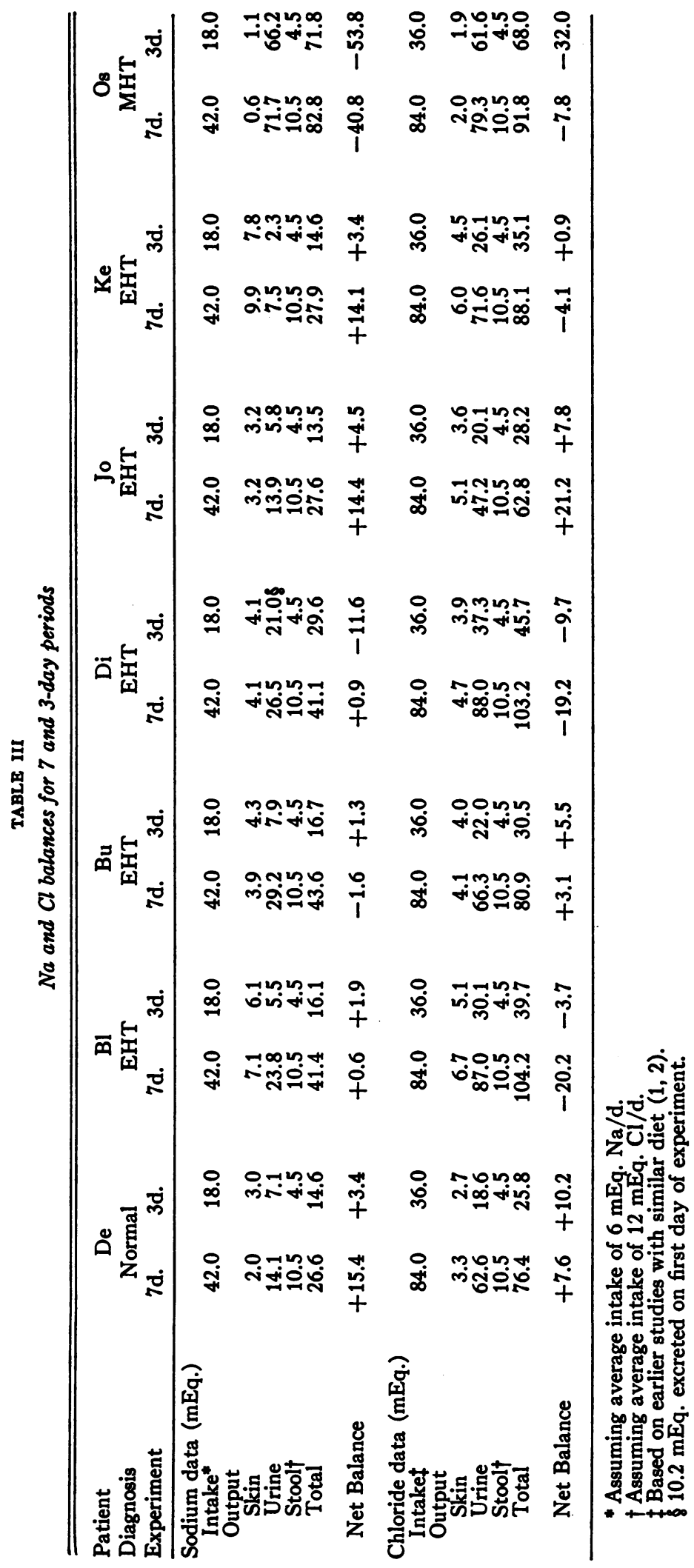



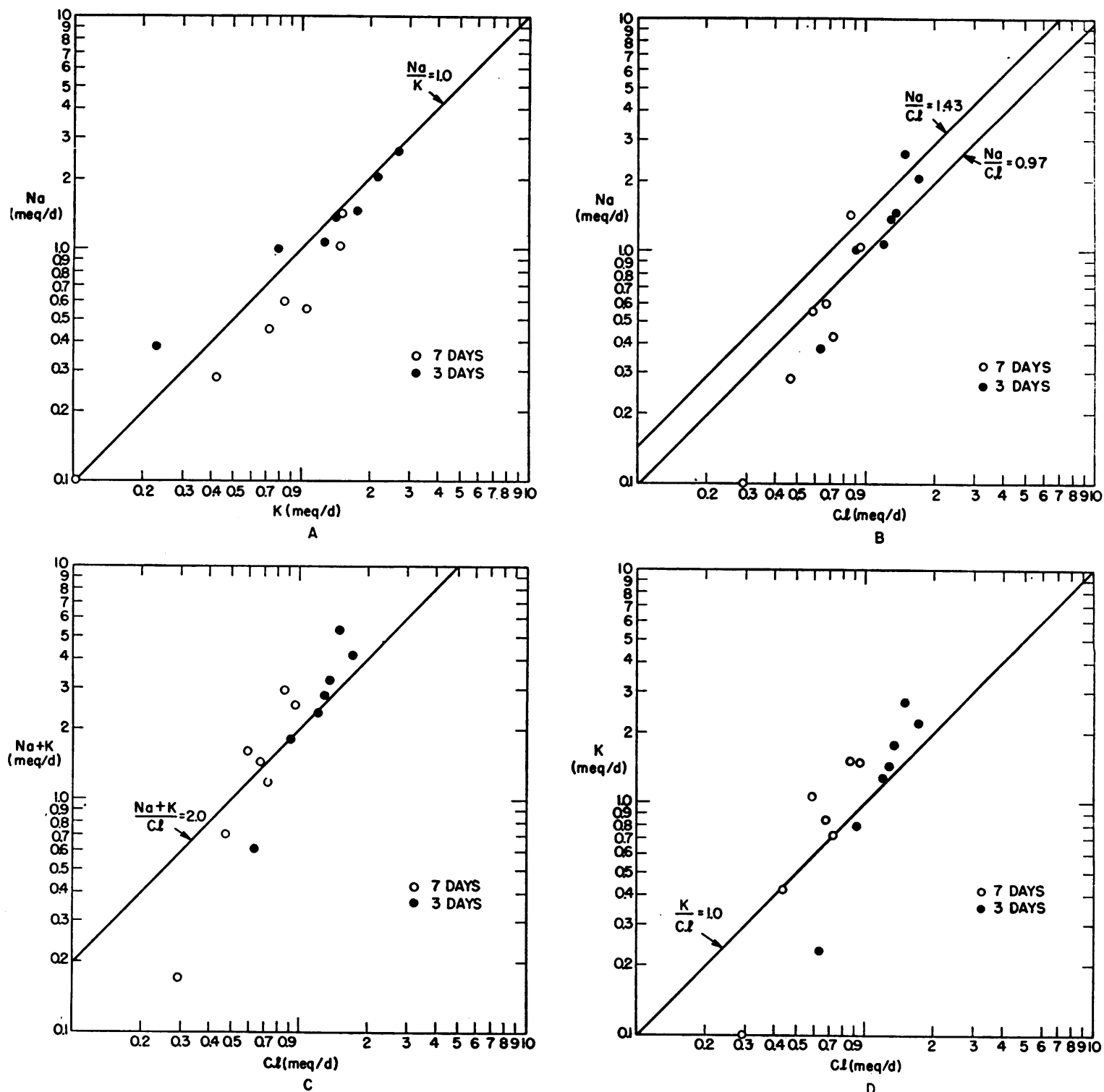

Fig. 1. Ratios of Concentrations of Daily Electrolyte Loss from Skin

Since the data are plotted logarithmically, constant ratios will be on parallel straight lines. Points below any line will have lower ratios than that indicated by the line, and points above a line, higher ratios. Graph $A=N a / K$, Graph $\mathrm{B}=\mathrm{Na} / \mathrm{Cl}$, Graph $\mathrm{C}=\frac{\mathrm{Na}+\mathrm{K}}{\mathrm{Cl}}$, and Graph $\mathrm{D}=\frac{\mathrm{K}}{\mathrm{Cl}}$.

The two numerical ratios, shown in Graph B, are the ranges quoted by Robinson (14) for normal sweat values.

\section{Balance data}

In Table III, balance calculations for $\mathrm{Na}$ and $\mathrm{Cl}$ on this group have been made using stool excretion data from previous similar experiments $(1,2)$. Because of the wide variations possible in intake, balance calculations were not made for $K$. It will be seen that all of the patients were in approximate $\mathrm{Na}$ balance with the exception of patient Os, and the three-day period in patient
$\mathrm{Di}$, whose long-term balance was positive as indicated by urinary excretion and plasma $\mathrm{Na}$. The negative balance of Os will be noted under CORRELATIONS and requires no amplification. The intake data for chloride are less reliable than those for $\mathrm{Na}$ since $\mathrm{Cl}$ intake was dependent solely upon the limitation imposed by the $\mathrm{Na}$ restriction. Although several patients show slight negative balances for these short-term studies, with the ex- 
ception of Os, there was no long-term evidence of such as indicated by urine excretion or significant decrease in plasma $\mathrm{Cl}$.

\section{CORRELATIONS}

In the accompanying graphs the electrolyte ratios $\frac{\mathrm{Na}}{\mathrm{K}}, \frac{\mathrm{Na}}{\mathrm{Cl}}, \frac{\mathrm{Na}+\mathrm{K}}{\mathrm{Cl}}$ and $\frac{\mathrm{K}}{\mathrm{Cl}}$ for the skin collections are plotted, and considering the small absolute amounts involved, the ratios in the two experiments were in surprisingly good agreement for any single individual. The $\frac{\mathrm{Na}}{\mathrm{K}}$ and $\frac{\mathrm{Na}}{\mathrm{Cl}}$ ratios much more closely approximate those found in sweat after $\mathrm{Na}$ restriction (1), and the administration of adrenal control hormones (10-12) than those which might be expected to come through the skin by diffusion of extracellular fluid with insensible perspiration.

Measurements of both plasma $\mathrm{Na}$ and $\mathrm{Cl}$ made five and eight days after the completion of the seven and three-day periods, respectively, showed no statistically significant changes from the control values, except in patient Os with impaired renal function: in him plasma $\mathrm{Na}$ and $\mathrm{Cl}$ levels immediately before $\mathrm{Na}$ restriction were 142.5 and $100.2 \mathrm{mEq}$. per liter, respectively. Ten days later they were 135.8 and $86.2 \mathrm{mEq}$. per liter. The values after the two studies were: 7 days- $\mathrm{Na}$ 123.5, $\mathrm{Cl} 84.3$; 3 days- $\mathrm{Na} 129.7, \mathrm{Cl} 85.2 \mathrm{mEq}$. per liter. The patient had received a total of 288 mEq. added $\mathrm{NaCl}$ orally by the time of the last plasma chloride study. With this single exception it may be said that the low skin losses of $\mathrm{Na}$ and $\mathrm{Cl}$ were not associated with a chronic decrease in extracellular concentrations.

\section{DISCUSSION}

These observations have shown that quite small amounts of $\mathrm{Na}, \mathrm{Cl}$, and $\mathrm{K}$ were lost through the skin under the conditions of this experiment. From the data of DuBois and DuBois (13), it was estimated that the areas not included by the present study amounted to approximately 15 per cent of the total body surface. It is not possible to state this fraction's contribution to the total electrolyte loss, but addition of 15 to 25 per cent over the listed values would not affect the interpretations, nor would calculations based on loss per unit of surface area. These data indicate that the minimal dermal loss of about $0.2 \mathrm{mEq}$. $\mathrm{Cl}$ per hour quoted by Robinson and Robinson (14) for normal individuals was diminished to levels of roughly 0.01 to $0.1 \mathrm{mEq}$. per hour in these patients. There are very few previous studies with which the present data may be compared, since interest has centered largely on the electrolyte losses associated with sweating after exercise or exposure to heat (e.g., 12, 15, 16, 17). In this group, neither of these factors was important since gross sweating did not occur. Indeed, it is questionable whether the quantities measured here represent the electrolytes of sweat or those salts which came through the skin in association with insensible perspiration as well as from desquamated epithelial cells and sebaceous secretion (18). As noted under CoRrelations, the $\frac{\mathrm{Na}}{\mathrm{K}}$ and $\frac{\mathrm{Na}}{\mathrm{Cl}}$ ratios, at least, are more suggestive of sweat ratios than diffusion products. But, whether the loss of electrolytes came chiefly from unnoticed perspiration, or via so-called insensible perspiration, it is evident that such loss is low, and except for Benedict's fasting patient (5), generally lower than previously reported $(3,4,18)$. It seems fair to conclude, then, that at least in the absence of marked sweating, skin losses of these electrolytes on this regimen may usually be disregarded, even after considerable periods of restriction.

It is of interest that the absolute amounts of electrolytes washed from the skin in both experiments were very similar in any single individual; when calculated on a per diem basis, the losses of the three-day experiment of course exceeded those in the seven-day study. There is evidence that with rise in skin temperature more chloride is excreted in the sweat at least (19) ; since skin temperature is partly a function of the ambient temperature, it is possible that the mean increase of $12^{\circ}$ in maximal outside temperatures accounted for the larger daily excretion of electrolytes in the shorter experiment, either as the result of unnoticed sweat in small amounts or by diffusion with insensible perspiration (18). Another intriguing possibility, however, is that the electrolytes were reabsorbed through the intact skin by a process the reverse of that which occurs when the electrolytes diffuse outwards during insensible perspiration.

Several preliminary experiments which were 
done with $\mathrm{Na}^{24}$ to test this conjecture indicated quite clearly that sodium could be absorbed through intact skin. If this is true for $\mathrm{Na}$, it may be true for other electrolytes as well. No evidence is available to indicate whether such absorption occurred via the sweat glands or directly through the skin. From this, however, the thesis emerges that in the absence of frank sweating at some dermal concentration of electrolyte, which concentration may vary perhaps with both body location and individual, reabsorption would begin and continue until the excess electrolyte was removed.

\section{SUMMARY}

1. The loss of $\mathrm{Na}, \mathrm{K}$, and $\mathrm{Cl}$ from the skin has been measured in seven patients-six hypertensives and one normal-all of whom had been on a low $\mathrm{Na}$, low $\mathrm{Cl}$, normal $\mathrm{K}$ diet for periods ranging from 26 to 150 days when the experiments began.

2. The measured losses amounted to 0.09 to $2.59 \mathrm{mEq}$. per day, 0.08 to $2.69 \mathrm{mEq}$. per day, and 0.29 to $1.71 \mathrm{mEq}$. per day for $\mathrm{Na}, \mathrm{K}$, and $\mathrm{Cl}$, respectively.

3. Among the seven patients the one with malignant hypertension lost the smallest amounts of these electrolytes from the skin; the normal control had values roughly mid-way between the extremely low values of that patient and the greater losses of the five patients with essential hypertension.

4. The data indicate that despite the rigid dietary restrictions, electrolyte balance was possible among the six members with good renal function.

5. The skin washings for the seven and threeday periods contained very similar amounts of electrolytes. Therefore, it was proposed that at some unknown concentration on the skin surface, reabsorption of electrolyte might begin and continue until the usual situation had been reestablished.

\section{ACKNOWLEDGMENT}

We wish to thank Mrs. Miriam Brown for her technical assistance.

\section{REFERENCES}

1. Dole, V. P., Dahl, L. K., Cotzias, G. C., Eder, H. A., and Krebs, M. E., Dietary treatment of hypertension. Clinical and metabolic studies of pa- tients on the rice-fruit diet. J. Clin. Invest., 1950, 29, 1189.

2. Dole, V. P., Dahl, L. K., Cotzias, G. C., Dziewiatkowski, D. D., and Harris, C., Dietary treatment of hypertension. II. Sodium depletion as related to the therapeutic effect. J. Clin. Invest., 1951, 30, 584.

3. Freyberg, R. H., and Grant, R. L., Loss of minerals through the skin of normal humans when sweating is avoided. J. Clin. Invest., 1937, 16, 729.

4. Arn, K. D., and Reimer, A., Minimal sodium losses through the skin. J. Clin. Invest., 1950, 29, 1342.

5. Benedict, F. G., A study of prolonged fasting. Carnegie Inst. of Washington, 1915, Publication No. 203, p. 233.

6. Miller, E. C., Plant Physiology. 2d ed., New York, McGraw-Hill Book Co., Inc., 1938, p. 288.

7. Van Slyke, D. D., and Hiller, A., Application of Sendroy's iodometric chloride titration to proteincontaining fluids. J. Biol. Chem., 1947, 167, 107.

8. Sendroy, J., Jr., Microdetermination of chloride in biological fluids, with solid silver iodate. II. Titrimetric analysis. J. Biol. Chem., 1937, 120, 405.

9. Van Slyke, D. D., Nomogram for correction of low urine chloride values determined by the silver iodate reaction. J. Biol. Chem., 1947, 171, 467.

10. Conn, J. W., Louis, L. H., Johnston, M. W., and Johnson, B. J., The electrolyte content of thermal sweat as an index of adrenal cortical function. $J$. Clin. Invest., 1948, 27, 529.

11. Conn, J. W., Electrolyte composition of sweat. Clinical implications as an index of adrenal cortical function. Arch. Int. Med., 1949, 83, 416.

12. Conn, J. W., The mechanism of acclimatization to heat in Advances in Internal Medicine, Dock, W., and Snapper, I., Editors. New York, Interscience Publishers, Inc., 1949, vol. 3, p. 373.

13. DuBois, D., and DuBois, E. F., The measurement of the surface area of man. Arch. Int. Med. 1915, $15,868$.

14. Robinson, S., and Robinson, A. H., Chemical composition of sweat. Physiol. Rev., 1954, 34, 202.

15. Moss, K. N., Some effects of high air temperatures and muscular exertion upon colliers. Proc. Roy. Soc., London, s.B., 1924, 95, 181.

16. Dill, D. B., Life, Heat and Altitude. Cambridge, Harvard University Press, 1938, p. 39.

17. McCance, R. A., Experimental sodium chloride deficiency in man. Proc. Roy. Soc., London, s.B., 1936, 119B, 245.

18. Hancock, W., Witehouse, A. G. R., and Haldane, J. S., The loss of water and salts through the skin, and the corresponding physiological adjustments. Proc. Roy. Soc., London, s.B., 1929, 105, 43.

19. Robinson, S., Gerking, S. D., Turrell, E. S., and Kincaid, R. K., Effect of skin temperature on salt concentration of sweat. J. Applied Physiol., 1950, 2, 654 . 